\title{
Delayed Gastric Emptying as a Complication of Whipple's Procedure: Could it be Much Less Frequent than Anticipated? Could the Definition Be Revised? A Single Center Experience
}

\author{
Whipple Ameliyatının Bir Komplikasyonu Olarak Gecikmiş Mide \\ Boşalması: Beklenenden Çok Daha Az Olabilir mi? Tanım Revize \\ Edilebilir mi? Tek Merkez Deneyimi
}

\author{
Mikail CAKIR $\odot$, Muzaffer AKINCI $\odot$, Okan Murat AKTURK $\odot$
}

Ethics Committee Approval: This study was approved by the Haseki Training and Research Hospital, Clinical Studies Ethics Committee, October 4, 2017; 2017/558.

Conflict of interest: The authors declare that they have no conflict of interest.

Funding: None.

Informed Consent: Informed consent was taken from the patients enrolled in this study.
Cite as: Cakir M, Akinci M, Akturk OM. Delayed gastric emptying as a complication of Whipple's procedure. Could it be much less frequent than anticipated? Could the definition be revised? A single center experience. Medeni Med J. 2020;35:181-7.

\begin{abstract}
Objective: Whipple's procedure for periampullary tumors has significant risks and complications. Delayed gastric emptying has the highest rate. Although the International Study Group of Pancreatic Surgery defined (ISGPS) this entity, multiple definitions still exist among authors. This study aims to revise the definition.

Method: Seventy-three consecutive patients were analyzed for complications, particularly delayed gastric emptying. All patients underwent a standardized surgery. Procedures used for total pancreatectomies and benign diseases were excluded.

Results: A total of 73 patients were included in the study. Intra-abdominal complications were observed in 15 (20.6\%) patients. Grade $C$ delayed gastric emptying was observed in only one (1.4\%) patient. Grade $A$ and $B$ disease were observed in three (4.1\%) patients. However, they responded well to conservative methods, causing no extra morbidity.

Conclusion: Grade $A$ and $B$ delayed gastric emptying can be observed after any gastrointestinal surgery. These patients respond well to simple conservative methods with nasogastric intubation. Drainage of the intra-abdominal collection resolves the emptying problem (if any). Only grade $C$ disease without other intra-abdominal complications can be accepted as a complication of this procedure. ISGPS definition does not include the cause. Thus, the definition and grading can be revised.
\end{abstract}

Keywords: Whipple's procedure, delayed gastric emptying, ISGPS definition of delayed gastric emptying

öz

Amaç: Periampuller tümörler için Whipple prosedürünün önemli riskleri ve komplikasyonları vardır. Gecikmiş mide boşalması en yüksek orana sahiptir. Uluslararası Pankreas Cerrahisi Çalışma Grubu (ISGPS) bunu tanımlasa da, otörler arasında çok sayıda tanım hala mevcuttur. Bu çalışma tanımı revize etmeyi amaçlamaktadır.

Yöntem: 73 ardıssık hasta, özellikle gecikmiş mide boșalması olmak üzere komplikasyonlar açısından analiz edildi. Tüm hastalara standart bir ameliyat uygulandı. Total pankreatektomili ve benign hastalıkların olduğu prosedürler hariç tutuldu.

Bulgular: Toplam 73 hasta çalışmaya dahil edildi. $15(\% 20,6)$ hastada intraabdominal komplikasyon görüldü. Sadece bir $(\% 1,4)$ hastada Grade $C$ gecikmiş mide boşalması gözlendi. Grade A ve $B$ ise üç $(\% 4,1)$ hastada gözlendi, bu hastalar konzervatif yöntemlere iyi yanıt verdiler ve ekstra morbidite görülmedi.

Sonuç: Grade $A$ ve $B$ gecikmiş mide boşalması herhangi bir gastrointestinal cerrahi sonrası görülebilmektedir. Bu hastalar nazogastrik tüp yerleștirilmesi ile basit konzervatif yöntemlere iyi yanıt verir. Karın içi koleksiyonun drenajı, varsa boşalma sorununu çözer. Diğer intraabdominal komplikasyonlar olmaksızın sadece grade $C$ bu prosedürün bir komplikasyonu olarak kabul edilebilir. ISGPS tanımı nedeni içermiyor. Dolayısıyla tanım ve derecelendirme revize edilebilir.

Anahtar kelimeler: Whipple prosedürü, Gecikmiş mide boşalması, ISGPS Gecikmiş mide boşalması tanımı
Received: 4 June 2020

Accepted: 13 August 2020

Online First: 30 September 2020

Corresponding Author: M. Cakir ORCID: 0000-0001-8087-5680 University of Health Sciences Haseki Training and Research Hospital, Department of General Surgery, Istanbul, Turkey drmikailcakir1@gmail.com

M. Akinci ORCID: 0000-0002-7068-6816 O.M. Akturk ORCID: 0000-0002-0759-3756 University of Health Sciences Haseki Training and Research Hospital, Department of General Surgery, Istanbul, Turkey 


\section{INTRODUCTION}

Whipple's procedure (WP) is the best curative option for malignancies of the periampullary region involving the pancreatic head, ampulla of Vater, duodenum, and the distal bile duct. These tumors are difficult to deal with; therefore, they need to be treated with a multimodal approach.

Complications associated with WP such as, pancreaticojejunostomy, hepaticojejunostomy, gastrojejunostomy and chylous fistulas, delayed gastric emptying (DGE), intra-abdominal collections and abscesses, wound infection, cardiopulmonary complications, and thromboembolic events occur at a rate between $30 \%$ and $45 \%{ }^{1}$. Different techniques and medical treatments are being evaluated to decrease the complications.

In the literature, the incidence of DGE varies widely, ranging from $5 \%$ to $61 \%^{2-5}$. DGE is the most common complication observed after WP in some studies with high volume series ${ }^{6,7}$. The exact pathogenesis of this disease is unknown. Several risk factors appear to cause DGE, such as male predilection, diabetes mellitus, smoking, fistulas, intra-abdominal collections, vagal denervation of the stomach, duodenal resection, and surgical techniques. Avoidance of intra-abdominal complications can reduce $\mathrm{DGE}^{2,3,5,8,9}$.

Herein, we present an article on DGE in addition to other complications. Grade A and B (according to the ISGPS definition) DGE patients respond well to conservative methods without any extramorbidity as it can be observed after any gastrointestinal tract surgery. Emptying problems arising from intra-abdominal complications are secondary entities and different from WP related DGE itself $^{10}$. Differences in definition are still discussed in recent literature ${ }^{9,11}$. It would be better to separate secondary gastric emptying problems from DGE of WP, so that, surgeons' attention will turn to DGE from WP itself. We discuss whether or not the definition can be revised.

\section{MATERIAL and METHODS}

The study was approved by the hospital's ethics committee with full compliance to the 2000 revision of the Declaration of Helsinki. Written consents of the patients were obtained on the first day of hospitalization.

Seventy-three consecutive patients who successfully underwent WP for malignancies between January 1, 2014 and December 31, 2018 in Haseki Training and Research Hospital, were retrospectively analyzed. A five-year analysis related to follow-up and complications, particularly DGE, was performed. Seventy-three WPs were included for homogeneity of the study. Five patients who underwent WPs with indications of severe tumoral inflammation that were treated with total pancreatectomy $(n=2)$, benign conditions (chronic pancreatitis and pancreatic duct stone) diagnosed based on final pathological examinations $(n=2)$ and a pancreatic head gun-shot wound $(n=1)$.

Patient characteristics such as sex, age, primary symptoms, emergent or elective outpatient conditions, existing cholangitis, comorbidities, and smoking were noted. Intra-abdominal complications with follow-up and final pathological examinations were recorded. DGE-related factors were investigated.

All surgeries were performed by the same hepatopancreatobiliary surgeon along with a general surgeon of the hospital. The study was conducted in an academic manner. Statistical analysis was not performed due to the inadequate sample size.

\section{Operation and follow-up}

WP was performed by antrectomy at the incisura angularis (Figure 1). None of the patients underwent pylorus-preserving WP. This is our practice and preference. The proximal jejunal segment was brought trans-mesocolically, and a series of anastomoses were performed in the retrocolic 
position. Pancreaticojejunostomy, hepaticojejunostomy, and gastrojejunostomy anastomoses were also performed. Pancreaticojejunostomy was the first anastomosis made $5 \mathrm{~cm}$ proximal to the closed end of the jejunum. Hepaticojejunostomy was performed $10 \mathrm{~cm}$ proximal to the pancreaticojejunostomy and gastrojejunostomy was realized $40 \mathrm{~cm}$ proximal to the hepaticojejunostomy. Roux-en-Y reconstruction was not preferred. Pancreaticojejunostomy and hepaticojejunostomy anastomoses were performed using the end-to-side (duct-to-mucosa) technique with 5-0 polydioxanone sutures. The lower $3 \mathrm{~cm}$ of the antrectomy site was used for the gastrojejunostomy anastomosis. Nasogastric tube (NGT) was placed $30 \mathrm{~cm}$ distal to the gastrojejunostomy anastomosis, and administration of water and enteral nutrition via this NGT was commenced on postoperative day (POD) 2. NGT was removed and oral feeding was commenced on POD 4. Two drains were placed and removed on POD 6-7 after confirming the absence of fistulas.

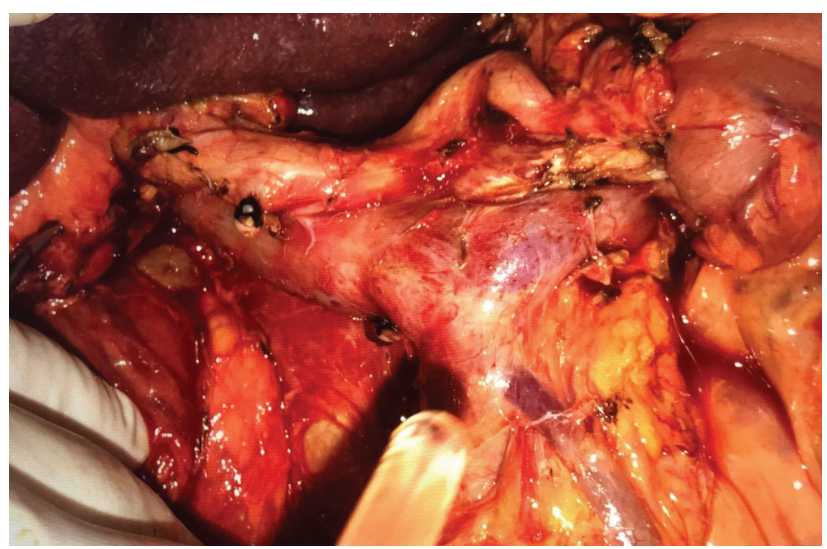

Figure 1. Whipple's procedure, completed resection.

Patient follow-up was recorded on daily basis. Morbidity related complications were closely followed and early intervened. Perioperative mortality was defined as death within 30 days of the surgery.

\section{DGE Definition}

High NGT drainage, vomiting, or intolerance to oral feeding are the main presentations of DGE.
Most studies are related to the duration of nasogastric intubation and/or the need for reinsertion of an NGT. ISGPS defined and graded DGE according to the duration of nasogastric intubation; 4-7 PODs as Grade A (mild), 8-14 PODs as Grade B (moderate), and beyond 14 PODs as Grade C (severe) $)^{12,13}$.

\section{RESULTS}

A total of 73 patients, 43 (59\%) males and 30 (41\%) females underwent WP for periampullary malignancies. The mean age was 63.2 years (range, 42 80 years). The patients with comorbidities $(n=49$ : $67.1 \%)$ included cases with with diabetes $(n=21$ : $28.7 \%$ ), ischemic heart disease or hypertension $(\mathrm{n}=14: 19.1 \%)$, chronic obstructive lung disease $(n=12: 16.4 \%)$, Alzheimer's disease $(n=1: 1.4 \%)$, and history of colon cancer ( $\mathrm{n}=1: 1.4 \%)$.

Jaundice was the most common symptom observed in 30 (41\%) patients, and 14 (19.1\%) of them admitted to the emergency surgery unit with cholangitis. Fatigue, anorexia, weight loss, anemia, nausea/vomiting, and back pain were the other presenting symptoms. Twenty-five (34.2\%) patients were smokers (Table 1 ).

\section{Table 1. Patient characteristics.}

\begin{tabular}{ll}
\hline Total (n/\%) & $73(100)$ \\
Male (n/\%) & $43(59)$ \\
Female (n/\%) & $30(41)$ \\
Mean age (years) & 63.2 (range, 42-80) \\
Emergency/cholangitis (\%) & $14(19.1)$ \\
Outpatient/elective (n/\%) & $59(80.9)$ \\
Symptomatology & \\
Jaundice (n/\%) & $30(41)$ \\
Fatigue (n/\%) & $20(27.4)$ \\
Weight loss (n/\%) & $11(15)$ \\
Anemia (n/\%) & $9(12.3)$ \\
Nausea/vomiting (n/\%) & $7(9.5)$ \\
Back pain (n/\%) & $7(9.5)$ \\
Comorbities & \\
Diabetes mellitus (n/\%) & $21(28.7)$ \\
Ischemic heart disease/hypertension (n/\%) & $14(19.1)$ \\
Chronic obstructive lung disease (n/\%) & $12(16.4)$ \\
Alzheimer's disease (n/\%) & $1(1.4)$ \\
Previous other cancer (n/\%) & $1(1.4)$ \\
Smoking history & \\
Smoker (n/\%) & $25(34.2)$ \\
&
\end{tabular}


The results of the pathological examinations are given on Table 2 . The total intra-abdominal complication rate was $20.6 \%$ (Table 3 ). Three $(4.1 \%$ ) patients exited.

Table 2. Results of pathological examinations.

\begin{tabular}{ll}
\hline & $\mathbf{n}(\%)$ \\
\hline Adenocarcinoma of the pancreas & $42(57.5)$ \\
Intraductal papillary mucinous neoplasia & $2(2.7)$ \\
Neuroendocrine tumor of the pancreas & $2(2.7)$ \\
Adenocarcinoma of the duodenum & $4(5.5)$ \\
Adenocarcinoma of the duodenal papilla & $8(11)$ \\
Cholangiocarcinoma of the distal bile duct & $15(20.6)$ \\
Total & $73(100)$ \\
\end{tabular}

Table 3. Intra-abdominal complications.

\begin{tabular}{ll}
\hline & n (\%) \\
\hline Pancreatic fistula & $6(8.2)$ \\
Biliary fistula & $3(4.1)$ \\
Chylous fistula & $1(1.4)$ \\
Intra-abdominal collection & $4(5.5)$ \\
Delayed gastric emptying & $1(1.4)$ Grade C \\
Total & $15(20.6)$ \\
\hline
\end{tabular}

According to the ISGPS 2016 standardization of the PF grading system, grade A was observed in three $(50 \%)$, grade $B$ in one $(16.7 \%)$, and grade $\mathrm{C}$ in two (33.3\%) patients. Grade A patients were followed up conservatively, and oral feeding was continued. Grade B patients were treated with total parenteral nutrition and antibiotics. Nasogastric intubation continued for seven days with a daily drainage of approximately 500 cc. The fistula was controlled for seven days and oral feeding was commenced. Two grade $\mathrm{C}$ patients were followed up in the intensive care unit (ICU). NGTs were placed. One patient was discharged after POD 11 and oral feeding was commenced in the general surgery ward. The other grade $C$ patient died in the ICU due to uncontrolled sepsis. None of the PF patients developed DGE.

BF developed in three $(4.1 \%)$ patients, of which two $(66.6 \%)$ patients had daily bile drainage of approximately 400-500 cc. Oral feeding was discontinued for only two days without an NGT placement in these patients. After percutaneous transhepatic cholangiography (PTC) catheterization, oral feeding was commenced. The third patient, with a bile drainage of $750-1000$ cc was explored on POD 5 after rupture of the posterior anastomosis suture line. The anastomosis was reconstructed with the guidance of a PTC placed in the jejunum. Unfortunately, the fistula persisted and nasogastric intubation continued for 10 days, with a daily drainage of approximately 500 cc. After controlling the fistula on the tenth day, the NGT was removed and oral feeding was commenced. DGE did not develop in BF patients, and the NGT was placed only for controlling the fistula and performing radiologic interventions.

LF developed only in one (1.4\%) patient on POD 6, with a drainage of more than 1000 cc chylous fluid. Nasogastric intubation continued for 15 days. Total parenteral nutrition and octreotide injections without oral intake is our approach to treat LF. This patient did not develop DGE as well.

According to the ISGPS definition of DGE, grade A was observed in two (2.7\%) patients on POD 4 and 6; grade B in one (1.4\%) patient on POD 9, and grade $C$ in one (1.4\%) patient on POD 14.

Two patients with grade A developed intolerance to oral feeding (nausea and abdominal pain) within a few hours of the NGT removal that was placed during surgery. The NGTs were reinserted. The daily drainages were between 300-400 cc. Two days later, water and enteral feeding solution (30 ml/h) were commenced via an NGT, which was well tolerated by the patients. The NGTs were removed four days later.

One grade B patient developed vomiting on POD 9 , after five days of oral feeding. An NGT was reinserted, and left for two days with drainages of $250 \mathrm{cc}$ and $200 \mathrm{cc}$. Passage was checked using the contrast radiographic technique and normal passage was detected. Water and enteral feeding solution $(30 \mathrm{ml} / \mathrm{h}$ ) were commenced via an NGT. The NGT was removed on the fifth day, but was 
reinserted after a day due to postprandial vomiting. Firstly $350 \mathrm{cc}$ was drained. The amount of vomiting was lesser than $100 \mathrm{cc}$. After one day, the NGT was deliberately obstructed to check the gastric passage. No vomiting occurred, and the patients were fed via an NGT with water and enteral feeding solution $(30 \mathrm{ml} / \mathrm{h})$. The NGT was removed on the eighth day after resolution of the gastric emptying problem.

Ultrasonography was performed in these three patients and any intra-abdominal collections or fistulous complications were not observed. The grade A patients were 48- and 63-year-old females, with jaundice as their primary symptom. Both had not any comorbidities, and their pathological results were IPMN and distal bile duct cholangiocarcinoma. The grade B patient was a 69-year-old male smoker. His pathological result was ampullary adenocarcinoma. These patients were treated with nasogastric intubation and intravenous fluids.

Grade C DGE on POD 14 was only observed in one $(1.4 \%)$ patient with left hemicolectomy due to splenic flexure colonic adenocarcinoma. This patient also had no fistulous complication or intraabdominal collections. Several endoscopic examinations only showed alkaline bile reflux. We performed an exploration on POD 30 after seeing that NGT drainage and conservative prokinetic agents were futile. The gastrojejunal anastomosis was intact. Braun anastomosis was performed between the afferent and efferent loops of the jejunum to prevent bile reflux. However, Braun anastomosis failed and DGE persisted, which eventually resulted in the patient's death a year after WP.

DGE was not observed even in cases of intraabdominal collections or fistulous complications. Oral feeding was stopped only for drainage under the radiologic guidance.

DGE was not observed in any of the patients with chronic diseases.

\section{DISCUSSION}

DGE is the most common complication of WP mentioned in the literature. Its effect on mortality is negligible, but it lowers the quality of life and causes metabolic deterioration.

Since its incidence ranges between 5, and 61\% which means that there still exists confusion regarding its definition ${ }^{2-5,9}$. Despite the ISGPS definition $^{12}$ in 2007, its use has been varied among studies. In the review article by Panwar', it was reported that $80 \%$ of the studies used the ISGPS definition on DGE. In this review, the rates of grades A, B, and C DGE were given as $18.5 \%$, $7 \%$, and $6.2 \%$, respectively. It was also emphasized that many authors accept only grades B and C as DGE. In the original article by Zhou ${ }^{11}$, a metaanalysis comparing the pylorus-resecting and pylorus-preserving effects, its incidence reportedly ranged between $14 \%-61 \%$. The article added that the extent of this range was related to the multiple definitions or strict criteria of the ISGPS.

Most of the studies concerning DGE are related to surgical techniques such as pylorus-preservation or pylorus-resection ${ }^{11}$, Billroth 1 or 2 reconstruction ${ }^{14,15}$, with a Braun anastomosis ${ }^{16}$, antecolic or retrocolic gastrojejunal anastomosis $^{17}$, and Roux-en-Y reconstruction ${ }^{18}$.

Herein, we do not consider discussing these articles. The results show variations according to the experience of the center, the number of patients included, and the definition of DGE.

Intolerance to oral feeding observed in three (4.1\%) patients between POD 4-9, was thought to be a common problem in the postoperative course of any gastrointestinal surgery, including subtotal gastrectomies. These three patients' DGE are controversial, because the patients responded well to NGT drainage and conservative followup with intermittent feeding. Neither prolonged postoperative nor paralytic ileus was searched. 
Only intra-abdominal collection was searched with ultrasonography.

Fistulae (pancreatic, biliary, lymphatic-chylous) and even intra-abdominal collections did not cause DGE. In fact, intra-abdominal collections of any type may cause gastric emptying problems. The ISGPS definition and grading of DGE does not explain why it occurs. Therefore, a primary and secondary DGE can be defined separately ${ }^{10}$. When a fistula was observed, oral feeding was stopped until imaging methods finalized, and the fistula was controlled.

Five years of experience with 73 patients who underwent WP for periampullary malignancies revealed that the rate of incidence of DGE was not as high as that mentioned in the literature. Intolerance to oral feeding (delayed gastric emptying) until the fourteenth day was easily resolved by conservative methods. Patient characteristics, chronic diseases, and pathological results were not considered as predisposing factors.

DGE should be considered only in grade $C$ patients without any other intra-abdominal complications beyond postoperative 14 days. In our view, the most important factor for successfully preventing complications is to practice the same operative techniques that the surgeons are most familiar with. The patients in this study underwent the same operative technique of WP with antrectomy. In our opinion, gastrojejunustomy to antrectomy site provides a wider anastomosis and easier emptying. Preservation of pylorus leads to peristaltic difficulties. However, this is just a single center experience.

This study helps us understand that efforts to prevent DGE could lead to other complications, even increasing rates of mortality.

The limitation of this study is its small sample size not suitable for statistical analysis.

\section{CONCLUSION}

Grade A and B DGE can be observed in the postoperative course of WP, as observed in other gastrointestinal surgeries. Nasogastric intubation along with conservative methods is sufficient to treat these patients. Intra-abdominal collections causing difficulty in gastric emptying were resolved by drainage under the radiologic guidance. Grade C can be accepted as DGE without the presence of other intra-abdominal complications. ISGPS definition does not contain the cause. The definition and grading of DGE can be revised.

\section{REFERENCES}

1. He J, Ahuja N, Makary MA, et al. 2564 resected periampullary adenocarcinomas at a single institution: trends over three decades. HPB (Oxford). 2014;16:83-90. [CrossRef]

2. Giuliano K, Ejaz A, He J. Technical aspects of pancreaticoduodenectomy and their outcomes. Chin Clin Oncol. 2017;6:64. [CrossRef]

3. Nakamura T, Ambo Y, Noji T, et al. Reduction of the Incidence of Delayed Gastric Emptying in Side-to-Side Gastrojejunostomy in Subtotal Stomach-Preserving Pancreaticoduodenectomy. J Gastrointest Surg. 2015;19:1425-32. [CrossRef]

4. Kim DK, Hindenburg AA, Sharma SK, et al. Is pylorospasm a cause of delayed gastric emptying after pyloruspreserving pancreaticoduodenectomy?. Ann Surg Oncol. 2005;12:222-7. [CrossRef]

5. Eisenberg JD, Rosato EL, Lavu H, Yeo CJ, Winter JM. Delayed Gastric Emptying After Pancreaticoduodenectomy: an Analysis of Risk Factors and Cost. J Gastrointest Surg. 2015;19:1572-80. [CrossRef]

6. El Nakeeb A, Askr W, Mahdy Y, et al. Delayed gastric emptying after pancreaticoduodenectomy. Risk factors, predictors of severity and outcome. A single center experience of 588 cases. J Gastrointest Surg. 2015;19:1093100. [CrossRef]

7. Cameron JL, He J. Two thousand consecutive pancreaticoduodenectomies. J Am Coll Surg. 2015;220:530-6. [CrossRef]

8. Parmar AD, Sheffield KM, Vargas GM, et al. Factors associated with delayed gastric emptying after pancreaticoduodenectomy. HPB (Oxford). 2013;15:763-72. [CrossRef]

9. Panwar R, Pal S. The International Study Group of Pancreatic Surgery definition of delayed gastric emptying and the effects of various surgical modifications on the occurrence of delayed gastric emptying after pancreatoduodenectomy. Hepatobiliary Pancreat Dis Int. 2017;16:35363. [CrossRef]

10. Sato G, Ishizaki Y, Yoshimoto J, Sugo H, Imamura H, Kawasaki S. Factors influencing clinically significant delayed gastric emptying after subtotal stomach-preserving pancreatoduodenectomy. World J Surg. 2014;38:968-75. 
M. Cakir et al. Delayed Gastric Emptying as a Complication of Whipple's Procedure: Could it be Much Less Frequent than Anticipated? Could the Definition Be Revised? A Single Center Experience

\section{[CrossRef]}

11. Zhou Y, Lin L, Wu L, Xu D, Li B. A case-matched comparison and meta-analysis comparing pylorus-resecting pancreaticoduodenectomy with pylorus-preserving pancreaticoduodenectomy for the incidence of postoperative delayed gastric emptying. HPB (Oxford). 2015; 17:33743. [CrossRef]

12. Wente $M N$, Bassi C, Dervenis C, et al. Delayed gastric emptying (DGE) after pancreatic surgery: a suggested definition by the International Study Group of Pancreatic Surgery (ISGPS). Surgery. 2007;142:761-8. [CrossRef]

13. Malleo G, Crippa S, Butturini G, et al. Delayed gastric emptying after pylorus-preserving pancreaticoduodenectomy: validation of International Study Group of Pancreatic Surgery classification and analysis of risk factors. HPB (Oxford). 2010;12:610-8. [CrossRef]

14. Goei TH, van Berge Henegouwen MI, Slooff MJ, van Gulik TM, Gouma DJ, Eddes EH. Pylorus-preserving pancreatoduodenectomy: influence of a Billroth I versus a Billroth II type of reconstruction on gastric emptying. Dig Surg. 2001;18:376-80. [CrossRef]
15. Kurosaki I, Hatakeyama K. Clinical and surgical factors influencing delayed gastric emptying after pyloric-preserving pancreaticoduodenectomy. Hepatogastroenterology. 2005;52:143-8.

16. Xu B, Zhu YH, Qian MP, Shen RR, Zheng WY, Zhang YW. Braun Enteroenterostomy Following Pancreaticoduodenectomy: A Systematic Review and Meta-Analysis [published correction appears in Medicine (Baltimore). 2015 Sep;94(37):1] [published correction appears in Medicine (Baltimore). 2016 Jun 17;95(24):e2208]. Medicine (Baltimore). 2015;94:e1254. [CrossRef]

17. Sahora K, Morales-Oyarvide V, Thayer SP, et al. The effect of antecolic versus retrocolic reconstruction on delayed gastric emptying after classic non-pylorus-preserving pancreaticoduodenectomy. Am J Surg. 2015;209:102835. [CrossRef]

18. Uzunoglu FG, Reeh $M$, Wollstein R, et al. Single versus double Roux-en-Y reconstruction techniques in pancreaticoduodenectomy: a comparative single-center study. World J Surg. 2014;38:3228-34. [CrossRef] 